\title{
The Impact of Home Equity and Housing Provident Fund on the Household's Stock Investment
}

\author{
Hanjuan Zhu \\ Business School of Nanjing Normal University, Nanjing, China \\ Email: 324257399@qq.com
}

How to cite this paper: Zhu, H.J. (2019) The Impact of Home Equity and Housing Provident Fund on the Household's Stock Investment. Open Journal of Social Sciences, 7, 222-240.

https://doi.org/10.4236/jss.2019.78016

Received: July 10, 2019

Accepted: August 17, 2019

Published: August 20, 2019

Copyright (อ 2019 by author(s) and Scientific Research Publishing Inc. This work is licensed under the Creative Commons Attribution International License (CC BY 4.0).

http://creativecommons.org/licenses/by/4.0/

\section{(c) (i) Open Access}

\begin{abstract}
Based on the (CHFS) data of Chinese household finance survey, this paper divides the housing wealth of residents into housing net value and housing loan. On this basis, adding the virtual variable of whether to own provident fund or not, Probit model and Tobit model are used to investigate the change of housing net value and the influence of owning housing provident fund on the participation of family stock market. The empirical results show that the increase of net housing value will significantly increase the proportion of households participating in the stock market and the shareholding rate. Families with provident fund accounts are also more willing to join the stock market than those without provident fund accounts, and their shareholdings are higher.
\end{abstract}

\section{Keywords}

Home Equity, Housing Provident Fund, Stock Market Participation, Portfolio Choice

\section{Introduction}

Generally speaking, housing wealth and stock assets are two areas where household assets are more concentrated. In Europe and the United States, the stock market has become the main investment field of foreign residents because of its sound basic system and high dividend ratio. Although the Dow Jones industrial average plunged 55 per cent from its highest of 14,279 points in 2007 to a 12-year low of 6470 as a result of the 2007 subprime crisis, it is now up to a new high of 26,635 (October 2018). The real estate market because of its high circulation link tax rate, coupled with a more perfect housing security system and lower 
profit range, the attraction of investors is not great.

The situation in China is very different, with the Shanghai index falling from a high of 6124 points in 2007 and hovering around 2588 points by 2018, even if it hit a high of 4037 points on June 3, 2015. While stocks fell, house prices in China's first-tier cities, such as Beijing, Shanghai, Guangzhou and Shenzhen, rose rapidly, and second-tier cities began to rise after the upward trend in first-tier cities slowed. According to data from 70 large and medium-sized cities released by the National Bureau of Statistics in June 2018, the prices of new and secondhand houses in second-tier cities rose 6.3 percent and 4.6 percent, respectively (Wang Cunfu, 2018). In theory, the reason why housing is preferred by families is that housing not only has the basic attribute of consumer goods, but also has the investment attribute of maintaining and increasing value. As consumer goods, housing can bring lasting benefits to families. According to the survey of relevant industry institutions, the housing useful life of the average family is more than 8 years; as an investment product, housing occupies a large share of household assets, and the fluctuation of its value is bound to cause great changes in household wealth. The development of the real estate market and the downturn of the stock market have aroused the thinking of researchers. Some researchers believe that the housing market has a certain inhibitory effect on the financial market. To test this idea, a more microscopic question arises: "how does housing wealth affect household stock market participation and stock holdings?"

Housing provident fund is a personal housing provident fund specially used for housing consumption and is a part of family income. And because of the special characteristics of its special funds (that is, the storage period can only be used for the purchase, construction, overhaul of self-occupied housing, or payment of rent), it not only affects the purchase of family housing, And reducing monthly disposable income as a result of contributions to provident funds may also have an impact on the financial decisions of households. Whether the family has a provident fund or not also has two effects on the family stock holding rate. On the one hand, if a family has a provident fund account, it can reduce some of the mortgage loans that must be paid every month, reduce the burden of some housing loans, and make families more willing to enter the stock market. On the other hand, housing provident fund is a part of monthly household income, paying public deposit will reduce the final disposable income and reduce the willingness of families to enter the stock market. However, there is no clear answer from the relevant literature as to whether the ownership of provident fund has promoted or suppressed the participation of families in the stock market. The most direct significance of studying the changes of household stock market participation rate and stock holding rate caused by housing net value and provident fund ownership is that it is helpful for stock marketers to effectively analyze customer big data and recommend stocks to customers. Therefore, blind marketing and waste of resources can be avoided. 
Based on the model analysis, this paper uses the data of China Household Finance Survey (China Household Finance Survey, hereinafter referred to as CHFS) in 2015 to examine the changes of housing net value and the impact of owning housing provident fund on household stock market participation and shareholding rate. The study found that the increase in net housing value will significantly increase the participation of households in the stock market and the holding rate of stocks. Owning a provident fund also significantly improves the probability of family participation in the stock market and the stock holding rate.

This paper consists of six parts. The first part is the introduction, which briefly introduces the changes of China's housing market and stock market, as well as the possible impact of housing wealth and housing provident fund on stocks. Explain the significance and value of this study on the formulation of relevant policies and the impact of securities companies; The second part is the literature review, this part briefly introduces the domestic and foreign literature on the correlation between housing wealth and family participation in the capital market; The third part is the theoretical basis and model construction, through a simplified two-phase model and comparative static method to derive the relationship between the stock market participation rate and stock holding rate and the virtual variables of housing net value and whether to hold provident fund or not. The fourth part is the introduction of the data, which will explain the data and variables used in this paper; the fifth part is the regression setting; the sixth part is the results of empirical analysis to explain the economic significance of the correlation coefficient; the seventh part is the conclusions and recommendations.

\section{Literature Review}

Family finance is a hot field of financial research in recent years. The core of family finance is to maximize the long-term consumption utility of households by choosing different investment instruments to realize the intertemporal optimal allocation of assets owned by families.

As a kind of asset, real estate has a strong particularity. According to the results of previous researchers, the impact of housing wealth on household stock market participation rate and stock holding rate is uncertain. On the one hand, the appreciation of housing assets, as an important part of household assets, will increase the total wealth held by families and promote families to hold more risky assets. According to some early theories, people's relative risk aversion is the subtraction function of wealth. As a result, the increase in wealth brought about by the appreciation of housing will prompt families to invest more wealth in risky assets such as stocks (Cohn et al., 1795; Friend and Blume, 1975) [1]. As the most important asset of the family, the wealth effect of housing cannot be ignored, so it will promote the household holding of risky assets (Tobin, 1982) [2]. 
Other scholars believe that the increase in the level of household wealth caused by the increase in housing wealth can ease the mobility constraints of families (liao et al., 2012) [3]. It reduces the risk aversion of households (Peress, 2004) [4], thereby increasing the likelihood of family participation in the stock market and the share of investment in stocks. Moreover, in countries or regions with more developed credit, housing can be used as collateral to create conditions for families to invest in risky assets (Cardak and Wilkins, 2009). Chen Yongwei, Shi Yupeng and Quan Wuxie (2015) [5] conducted a study using data from the Chinese Household Finance Survey (CHFS) [6] in 2011. The results show that the increase in real estate wealth will significantly increase the probability of households participating in the financial market. It will also increase the proportion of households holding risky assets. Even after using the tool variable method and sub-sample regression to deal with the endogenesis problem, the above conclusion is still valid. Liu Tingting and Song Bingjie (2017) [7] believe that housing wealth has a positive impact on stock market participation and stock investment. According to the number of homeowners, the results show that the impact of housing wealth on stock market participation and share of stock investment is more obvious in a family. On the other hand, in the context of rising house prices, real estate will also expose families to higher risks and reduce their liquidity, prompting them to reduce their holdings of other risky assets. Using data from the 1989 US Consumer Finance Survey (Survey of Consumer Finances), Fratantoni (1998) [8] found that households who own homes need to deal with the risk of house price fluctuations, so households tend to hold a safer portfolio of financial assets. Grossman and Laroque (1990) [9] analyzed the impact of durable consumer goods such as housing on household asset allocation. They point out that holding higher-value consumer durables increases households' greater liquidity risk, so higher housing wealth may allow households to reduce their holdings of risky assets. Flavinand Yamashita (2002) [10] also believes that the liquidity constraints caused by home purchases will prevent households from investing in risky assets. Chettyand Szeidl (2007) [11] pointed out that deterministic consumption such as housing has the potential to increase the risk aversion of ordinary residents, thereby reducing the proportion of risky assets they hold. Yamashita (2003) [12] using data from the 1989 US Consumer Finance Survey, it was found that the higher the proportion of housing in household assets, the lower the share of stocks in household assets. Cocco (2005) [13] used income dynamic tracking (Panel Survey of Income Dynamice) data to find that house price risks crowd out stock investments, and this effect is particularly pronounced for young and poor households. In addition, (Chetty and Szeidl, 2010) [14] used 1990-2001 income and program participation to track (Survey of Income and Program Participation) data and found that home ownership has a twofold impact on asset allocation in the United States: the property effect of real estate causes households to hold more risky assets. Home mortgages, on the other hand, reduce households' holdings of risky assets. For the United States, the latter effect is dominant, so home ownership generally reduces 
residents' holdings of risky assets. (Fougeugre and Pouhes 2012) [15] repeated the study (Chetty and Szeidl 2010) [16] with French data, and obtained similar conclusions. Ye Dezhu et al. (2015) [17] focused on the empirical analysis of the influencing factors of household venture financial asset investment from the perspective of real estate ownership. The empirical results show that there is a critical value of $5 \%$ for the impact of real estate ownership on household risky financial asset investment, that is, real estate holding can promote the investment of less than $5 \%$ of risky financial assets. On the other hand, the impact on more than $5 \%$ of the investment in venture financial assets has a significant negative effect. (Chetty and Szeidl 2017) [19] separating housing wealth into housing value and housing net worth for the first time discusses their respective effects on household stock holding rates, using income and project tracking survey (Survey of Income and Program Participation) data from 1990 to 2008 (SIPP). When the housing value increases (the housing net value remains unchanged, that is, the housing loan becomes higher), the stock holding rate of the family decreases; When the net housing value rises (the housing value remains the same), the stock holding rate of the family increases. It shows that housing ownership has two effects on household asset allocation: wealth effect and risk effect. In theory, housing ownership may have two effects on household asset allocation. However, empirical studies in western developed countries show that the role of "wealth effect" is usually small and "risk effect", that is, housing ownership is more likely to make households reduce the holding of risky assets. The reason for this may be that in developed countries, the property market is more stable, the price increase is low, so the wealth effect is small. But in countries where house prices are soaring, such as China, the results may be different.

In addition to housing wealth, there are other factors that affect the investment of household risk assets: He Xingqiang et al. (2009) [18] examined the impact of "background risk" on residents' investment; Xing Chunbing (2011) [20] analyzed the stock market investment behavior of urban households in China by using CHIP data in 2002. The results show that there is a significant positive correlation between the probability of family participation in the stock market and the total wealth level of the family, the income of the head of household and the level of education, and there is an inverted U-shaped relationship with the age of the head of household. Income, wealth levels and age have a similar impact on the amount of stocks purchased by households; however, the impact of education levels has weakened. However, for the share of stocks in total household assets or financial assets, the effects of age and education are not significant in most models, and the coefficient of wealth level is significantly negative. Wu and Qi Tianxiang (2007) [21] analyzed the importance of liquidity and life cycle in residents' investment behavior. The main conclusions are as follows: 1) the impact of real estate on residents' participation in the stock market and investment portfolio is mainly the "crowding out" effect; 2) residents seldom choose stocks to hedge the risk of future cash flow; 3 ) the increase of wealth will not only increase the probability of participation in the stock market, but also increase 
the holding rate of stocks. Wu Weixing et al. (2010) [22] examined the impact of wealth and life cycle on residents' investment. The results show that the life cycle characteristics of household investment structure in China exist to some extent, but different assets are inconsistent. From a risk point of view, the investment structure of households is a "clock" structure, but in the case of extremely risky financial derivatives futures, young people are more willing to take risks. Housing investment has significantly squeezed out investors' investment in liquid assets; The impact of wealth on the investment structure of investors is quite obvious, in addition to futures, basically the increase in wealth, the participation rate of all kinds of risk assets will also increase, but there is an inverted U-shaped structure for low-risk assets such as cash and deposits. In addition, the main basis of family investment behavior is the current wealth, families rarely hedge the expected income in the future. Zhao Yuanyuan (2017) [23] studied the influencing factors of household venture financial asset investment and the differences between urban and rural areas by using the (CHFS) data of China Household Finance Survey in 2011. The main findings are: whether it is the impact on the diversity of household risk financial assets or the impact on the size of household risk financial assets, There is a significant positive correlation between financial literacy, education level, risk attitude, total assets and total income. There is a significant negative correlation between household debt and it. In addition, the factors of diversity and scale of household risk financial assets have a greater impact on urban families than rural families. Wu Weixing and $\mathrm{Lu}$ Xueliang (2013) [24] compared with foreign studies and concluded that Chinese families have more investment and real estate, and the stock investment participation rate of Chinese families has a negative correlation with age. Zhou Mingshan et al. (2011) [25] studied the impact of social interaction on stock market participation. In the areas (villages) where the proportion of local expenditure is high and the concentration of income distribution is high, social interaction plays a more significant role in promoting stock market participation. Wu Satellite and $\mathrm{Li}$ Yajun (2016) [26] found that different household structures do have an important impact on household asset allocation. Among them, single-generation families have more savings and invest in more risky assets than multi-generation families; families with unmarried children are more likely to invest in risky assets. Liu Jin (2015) [27] found that the proportion of risky financial assets began to decline after the household net asset value reached about 1.7 million, and the existence of credit constraints reduced the investment proportion of risky assets. The relationship between household real estate and risky financial assets is complementary rather than alternative; the proportion of risky financial assets begins to decline after the head of household reaches the age of about 58 .

\section{Model Construction}

\subsection{Model Setting}

With reference to Cocco (2005), this paper chooses a two-phase model, which combines the liquidity risk and price risk of housing to describe the impact of 
housing net value and provident fund on family stock market participation, respectively. Suppose a family has two periods of life: phase 0 , in which the family makes an investment allocation based on the value of the property $H_{0}$ and financial assets $L_{0}$ it owns, as well as the housing loans it has obtained, and the investment allocation made by the family according to the value of the property it owns and the financial assets it has obtained, as well as the amount of housing loans $M_{0}$ it has obtained. That is, to determine the proportion of stocks in financial assets. Then, according to the income obtained from the investment, the consumption is distributed according to the principle of utility maximization. The utility function of the family is as follows:

$$
E_{0} \frac{\left[c_{1}^{1-\mu} H_{1}^{\mu}\right]^{1-\gamma}}{1-\gamma}
$$

where $c_{1}$ is the daily consumption of the family in the first phase (such as food and other household expenses), $H_{1}$ is the value of the housing at stage 1 .

In period 0 , households can invest one part of their assets in risk-free assets with returns equal to $1+R_{f}=\exp \left(r_{f}\right)$ and other part in risky assets $\left(r \sim \mathrm{N}\left(\mu_{r}, \sigma^{2}\right)\right)$ with returns equal to $1+R=\exp (r)$, Assuming that the proportion of risky assets in non-housing financial assets is $\alpha \in[0,1]$, the return on the family's non-housing portfolio is $R_{p}=\alpha R+(1-\alpha) R_{f}$.

Suppose that at $t=0$, housing price $P_{0}=1$; While at $t=1, P_{1}=\exp \left(p_{1}\right)$, $p_{1} \sim \mathrm{N}\left(\mu_{p}, \sigma_{2}\right)$. The correlation coefficient of house price growth rate and growth rate of stock $\rho=\operatorname{corr}\left[p_{1}, r\right]$. Families choose alpha at $t=0$ to maximize itit under budget constraints:

$$
C_{1}+P_{1} H_{1}=\left(1+R_{p}\right) L_{0}+Y_{1}+H F_{1}+P_{1} H_{0}-\left(1+R_{m}\right) M_{0}
$$

where, $R_{m}$ is the loan interest rate, $Y_{1}$ is the disposable income of the family, and $H F_{1}$ is the provident fund (it is assumed that one part of the total household income is used for provident fund savings and other part is discretionary). Discounting the value in the budget constraint with the risk-free rate, that is $M=M_{0}\left(1+R_{m}\right) /\left(1+R_{f}\right), \quad Y=Y_{1} /\left(1+R_{f}\right), H F=H F_{1} /\left(1+R_{f}\right), \quad L=L_{0}$, $P H=P_{0} H_{0}, W=L+Y+H F+P H-M$.

\subsection{Determination of the Optimal Stock Holding Rate $\alpha$}

Suppose $W_{1}=\left(1+R_{p}\right) L_{0}+P_{1} H_{1}+Y_{1}+H F_{1}-M_{1}, C_{1}=u W_{1}$ and $H_{1}=(1-u) W_{1} / P_{1}$, so the expected household utility in the first period is

$$
V\left(W_{1}\right)=\left(\frac{\left[\mu^{\mu}(1-\mu)^{1-u}\right]^{1-\gamma}}{1-\gamma}\right) \cdot\left(\frac{w_{1}}{p_{1}^{u}}\right)^{1-\gamma}
$$

To maximize the family utility function is to maximiz $E_{0} \frac{\left[c_{1}^{1-\mu} H_{1}^{\mu}\right]^{1-\gamma}}{1-\gamma}$ by choosing appropriate $\alpha$. According to (Campbell and Viceira 2002) [31], first order logarithmic linearization of the first order condition $E\left[\left(R-R_{f}\right) \cdot V^{\prime}\left(W_{1}\right)\right]=0$ 
near alpha $=0$ is performed, sigma: $u_{r}-r_{f}+\frac{\sigma_{r}^{2}}{2}=-\operatorname{cov}\left(r, v^{\prime}\right), v^{\prime}$ is the log of $V^{\prime}, \operatorname{cov}\left(r, v^{\prime}\right)$ is the covariance of $r$ and $v^{\prime}$. so,

$$
V^{\prime}\left(W_{1}\right)=\left(\mu^{\mu}(1-\mu)^{1-u}\right)^{1-\gamma} W_{1}^{-\gamma} P_{1}^{(1-\beta)(\gamma-1)}
$$

Set $L_{1}=L_{0}\left(1+R_{p}\right)+Y_{1}-H F_{1}-\left(M_{1}-2 H F_{1}\right)$, simplifying to $L_{1}=L_{0}\left(1+R_{p}\right)+Y_{1}+H F_{1}-M_{1}$, and I'm going to log it linearly, so I can get

$$
l_{1}=\kappa^{\prime}+\eta_{1}\left(l_{0}+r_{p}\right)+\eta_{2}\left(y+h_{f}+r_{f}\right)+\left(1-\eta_{1}-\eta_{2}\right)\left(m+r_{f}\right)
$$

where $\kappa^{\prime}$ is a constant, these lowercase letters are logarithms of $L, Y, H F$, and $M$. Let $\eta_{1}=\frac{L}{L+Y+H F-M}$ and $\eta_{2}=\frac{Y+H F}{L+Y+H F-M}$, then to Log linearization

$$
W_{1}=\left(1+R_{p}\right) L_{0}+P_{1} H_{0}+Y_{1}+H F_{1}-M_{1}
$$

I can get

$$
\begin{aligned}
w= & \kappa^{\prime \prime}+(1-\rho) \eta_{1}\left(l+r_{p}\right)+(1-\rho) \eta_{2}\left(y+h_{f}+r_{f}\right) \\
& +(1-\rho)\left(1-\eta_{1}-\eta_{2}\right)\left(m+r_{f}\right)+\rho p_{1}
\end{aligned}
$$

where $k^{\prime \prime}$ is a different constant than $k^{\prime}$ and $\rho=\frac{P H}{L+P H+Y+H F-M}$

represents the share of housing value in total household wealth. $N P H$, which represents house equity, is equal to $P H-M$.

From

$$
\operatorname{cov}\left(r, v^{\prime}\right) \approx \gamma(1-\rho) \eta_{1} \cdot \alpha \sigma^{2}+(\gamma \rho-(\gamma-1) \mu) \operatorname{cov}\left[r, p_{1}\right]
$$

To

$$
E \mathfrak{r}-r_{f}+\frac{\sigma_{\mathfrak{r}}^{2}}{2} \approx \gamma(1-\rho) \eta_{1} \cdot \alpha \sigma^{2}+(\gamma \rho-(\gamma-1) \mu) \operatorname{cov}\left[r, p_{1}\right]
$$

So

$$
\begin{aligned}
\alpha= & \frac{E \mathfrak{r}-r_{f}+\frac{\sigma_{\mathfrak{r}}^{2}}{2}+(\mu(\gamma-1)-\gamma \rho) \operatorname{cov}\left[\mathfrak{r}, p_{1}\right]}{\gamma \cdot \sigma^{2} \eta_{1}(1-\rho)} \\
= & \frac{E \mathfrak{r}-r_{f}+\frac{\sigma_{\mathfrak{r}}^{2}}{2}+\left(\mu(\gamma-1)-\gamma \cdot \frac{P H}{P H+L+Y+H F-M}\right) \operatorname{cov}\left[\mathfrak{r}, p_{1}\right]}{\gamma \cdot \sigma^{2} \frac{L}{P H+L+Y+H F-M}} \\
= & \frac{\left(E \mathfrak{r}-r_{f}+\frac{\sigma_{\mathfrak{r}}^{2}}{2}\right)(N P H+L+Y+H F)}{\gamma \cdot \sigma^{2} \cdot L} \\
& +\frac{(\mu(\gamma-1)(N P H+L+Y+H F-M)-\gamma \cdot(N P H+M))}{\gamma \cdot \sigma^{2} \cdot L} \operatorname{cov}\left[\mathfrak{r}, p_{1}\right]
\end{aligned}
$$




\subsection{The Influence of Housing Net Value and Provident Fund on Family Stock Investment Strategy}

According to Equation (5), the first term represents the wealth effect, whose value is always greater than zero. If $\operatorname{cov}\left[\mathfrak{r}, p_{1}\right]=0$, there is no correlation between real estate income and financial asset income. At this point, the

$\frac{\mathrm{d} \alpha}{\mathrm{d} H F}=\frac{E \mathfrak{r}-r_{f}+\frac{\sigma_{\mathfrak{r}}^{2}}{2}}{\gamma \cdot \sigma^{2} \cdot L}>0$ means families with accumulation fund than family without accumulation fund tend to invest more money in the stock market; while $\mathrm{D}$ a $\frac{\mathrm{d} \alpha}{\mathrm{d} N P H}=\frac{E \mathfrak{r}-r_{f}+\frac{\sigma_{\mathrm{r}}^{2}}{2}}{\gamma \cdot \sigma^{2} \cdot L}>0$ means home-equity increase, family shares holding rate also increases. If $\operatorname{cov}\left[\mathfrak{r}, p_{1}\right] \neq 0$, it means that there is a correlation between real estate income and financial asset income. If the correlation coefficient between real estate income and current asset income is greater than 0 , it means that the income of the two assets changes in the same direction. As a result, households with more housing wealth may reduce their holdings of risky assets to offset the risk of both.

If the effect of hedging outweighs the wealth effect, there are $\frac{\mathrm{d} \alpha}{\mathrm{d} H F}<0$ and $\frac{\mathrm{d} \alpha}{\mathrm{d} N P H}<0$; If they are below the wealth effect, then the derivatives listed above can all be greater than zero.

If $\left(\operatorname{cov}\left[\mathfrak{r}, p_{1}\right]<0\right)$, then the wealth effect may be dominant, and at this time, both $\mathrm{d} \frac{\mathrm{d} \alpha}{\mathrm{d} H F}$ and $\frac{\mathrm{d} \alpha}{\mathrm{d} N P H}$ both are greater than 0 . According to the data of recent years, it can be concluded that: in the short term, the correlation between China's real estate market and stocks is small, and even there is a certain negative correlation for a period of time. Therefore, according to the above analysis, at least in the short term, the wealth effect of housing tends to dominate (Chen yongwei et al., 2015).The exogenous growth of housing accumulation fund and home equity increase the total household wealth in quantity, so they all have a positive effect on the stock holding rate. Similarly, to see the participation rate of the household stock market, we only need to calculate the size of $\frac{\mathrm{d} \alpha}{\mathrm{d} H F}$ and $\frac{\mathrm{d} \alpha}{\mathrm{d} N P H}$ near alpha $=0$. Similar to the previous analysis, at least in the short term, housing wealth dominates, resulting in both $\frac{\mathrm{d} \alpha}{\mathrm{d} H F}$ and $\frac{\mathrm{d} \alpha}{\mathrm{d} N P H}$ being greater than 0 near $\alpha=0$.

\section{Sample and Variable Selection}

All the data used in this study are from the (CHFS) 2015 survey data of the China Household Finance Survey. The sample included 37,289 families in 29 prov- 
inces and cities in China. The survey included, first, the characteristics of family members: age, sex, academic qualifications, marital status, religious beliefs, number of families living together, etc. Second, household assets and liabilities: assets include cash, deposits, bonds, funds, financial products, stocks, financial derivatives, foreign exchange investments, gold and loans. Liabilities include housing loans and education loans; third, family or individual insurance: including commercial insurance, medical insurance, old-age insurance and so on. Fourth, household or individual expenditure and income: mainly wage income and daily consumption expenditure.

CHFS also gave details of family-owned homes: the number of homes, the time of purchase, the purchase price, whether there are housing loans, current prices and other specific numerical information. After subtracting the current price from the purchase price, the net housing value was obtained and screened according to the net housing value, retaining the households with positive net value, and the final data included 15,765 households.

\subsection{Variable Selection}

\subsubsection{Explained Variable}

The main explanatory variables concerned in this paper are "participation in the stock market (ifinstock)", "stock_ratio of financial assets". Participation in the stock market "indicates whether a family has a stock account (in which it may not own stock), if so, take 1 , and vice versa, 0 , while "stock_ratio of financial assets" refers to the stock proportion of financial assets refers to the proportion of the stock share in the total financial assets, which is usually greater than 0 and less than 1.

\subsubsection{Explanatory Variable}

The main explanatory variables concerned in this paper are the net housing value of family ownership (net_value) and the ownership of provident fund (if_hf). In addition to the detailed introduction of the housing information owned by the family, CHFS also conducted a comprehensive survey of the amount of provident fund of the head of household and other information. Based on this information, we calculated the net value of the property owned by each family (the present value of the home minus the remaining loans). If the head of household owns a provident fund, it will be assigned 1, and if not, it will be 0 .

In fact, in addition to the main explanatory variables listed in this paper, there are many factors that affect the ratio of household stock market participation to stock ownership. These variables must be controlled, and the parameters obtained by model regression can effectively evaluate the impact of housing net value and provident fund on the participation rate and stock holding rate of household stock market. Therefore, according to the introduction of other relevant literature, this paper controls some variables that may be related to the explained variables (stock market participation rate and stock holding rate) or explanatory variables (net housing and provident fund ownership). First of all, the 
total amount of financial assets of households represents the liquidity of households, and its changes are bound to have an impact on household decisions in the stock market. In view of this, this paper controls the "total financial assets (TLA)". The rest of the annual household income minus the necessary household expenses can be entered into the capital market according to whether the family is willing to invest or not, so the amount of household income has a greater impact on the financial decisions of the family. Therefore, this paper controls the "annual household income (income)". The personal characteristics of the head of household and the number of family members will also affect the participation rate and stock holding rate of the household stock market. In order to solve this problem, this paper focuses on the "age (age) of the head of household". "Education level of head of household (education) 3" gender of head of household "(gender)", "level of risk preference of head of household (Risk_preference) 4", "number of family members living together", Variables such as "whether it is a rural hukou (Rural)" and "regional (Region) 5" are controlled.

\subsection{Descriptive Statistics}

According to the 15,765 households counted in this paper, the average value of the first suite (measured by 2015 prices) is 579,000, accounting for an average share of the total household wealth of $0.62 \%$. Because of its huge share, the change of its value is bound to have an impact on the household participation rate and stock holding rate in the stock market (Table 1).

According to Table 2, the stock market participation rate and stock holding rate of families are not only correlated with the housing equity and the provident

Table 1. Statistical description of variables.

\begin{tabular}{|c|c|c|c|c|}
\hline Variable name & Variable interpretation & Mean value & Standard deviation & Number of variables \\
\hline Ifinstock(IF_INS) & Whether or not to hold a stock account & 0.1243421 & 0.3299816 & 15,765 \\
\hline Stock_ratio (S_R) & Share of shares in financial assets & 0.0471166 & 0.1685844 & 15,765 \\
\hline net_house (N_H) & Net housing value (millions) & 0.5790148 & 0.888685 & 15,765 \\
\hline if_hf (I_H) & Whether or not to own a provident fund & 0.1586087 & 0.3653221 & 15,765 \\
\hline TLA & Total financial assets (millions) & 0.1193402 & 0.5336526 & 15,765 \\
\hline Income (I) & Total household income $(10,000)$ & 0.091923 & 0.2313909 & 15,765 \\
\hline $\operatorname{Num}(\mathrm{N})$ & Total number of family members & 3.129815 & 1.480082 & 15,765 \\
\hline Gender (G) & Gender of homeowner & 0.7449997 & 0.4358749 & 15,765 \\
\hline risk_prference (R_P) & Degree of risk preference of homeowners & 4.200879 & 1.282887 & 15,765 \\
\hline age & Age of homeowners & 52.45652 & 14.45724 & 15,765 \\
\hline (A) Education & Education level of homeowners & 3.587505 & 1.755044 & 15,765 \\
\hline (E) Region & Region & 1.615208 & 0.7917594 & 15,765 \\
\hline Rural & Are they urban residents? & 0.2508514 & 0.4335166 & 15,765 \\
\hline
\end{tabular}


Table 2. Variable correlation.

\begin{tabular}{|c|c|c|c|c|c|c|c|c|c|c|c|c|c|}
\hline & IF_INS & S_R & N_H & I_H & TLA & I & $\mathrm{N}$ & G & R_P & A & E & Region & Rural \\
\hline IF_INS & 1.0000 & & & & & & & & & & & & \\
\hline S_R & 0.7534 & 1.0000 & & & & & & & & & & & \\
\hline N_H & 0.3025 & 0.2425 & 1.0000 & & & & & & & & & & \\
\hline I_H & 0.3132 & 0.2388 & 0.2070 & 1.0000 & & & & & & & & & \\
\hline TLA & 0.2680 & 0.2459 & 0.2787 & 0.1005 & 1.0000 & & & & & & & & \\
\hline I & 0.2194 & 0.1873 & 0.2497 & 0.1467 & 0.4083 & 1.0000 & & & & & & & \\
\hline $\mathrm{N}$ & -0.0175 & -0.0133 & -0.0165 & -0.0355 & 0,0043 & 0.0528 & 1.0000 & & & & & & \\
\hline G & -0.0760 & -0.0542 & -0.1212 & -0.0169 & -0.0121 & -0.0137 & 0.1399 & 1.0000 & & & & & \\
\hline R_P & -0.3060 & -0.2549 & -0.1466 & -0.2263 & -0.1520 & -0.1614 & -0.0521 & -0.0044 & 1.0000 & & & & \\
\hline A & -0.1551 & -0.1046 & -0.0435 & -0.3155 & -0.0610 & -0.1103 & -0.1209 & 0.0158 & 0.3375 & 1.0000 & & & \\
\hline E & 0.3854 & 0.2920 & 0.3368 & 0.5159 & 0.1881 & 0.2130 & -0.0642 & -0.0739 & -0.3137 & -0.3936 & 1.0000 & & \\
\hline Region & -0.1188 & -0.0844 & -0.2470 & -0.0611 & -0.0707 & -0.0706 & 0.0400 & 0.0143 & 0.0121 & 0.0150 & -0.0953 & 1.0000 & \\
\hline Rural & -0.2009 & -0.1495 & -0.2606 & -0.2258 & -0.0939 & -0.1070 & 0.1142 & 0.1945 & 0.1396 & 0.1154 & -0.3512 & 0.1121 & 1.0000 \\
\hline
\end{tabular}

fund, but also correlated with the number of household liquid assets, family income, family members, gender, age, risk preference and education level. Therefore, adding these control variables into the model can promote the regression coefficient to be more accurate and reliable.

\section{Regression Setting}

According to the correlation of variables mentioned above, appropriate models are selected to discuss the influence degree of independent variables and control variables on dependent variables. This paper first examines the impact of home equity and provident fund on the participation rate of families in the stock market, and then analyzes their impact on the stock ownership rate. To investigate the influences of home equity and provident fund on the participation rate of families in the stock market, this paper chooses Probit regression. $Y_{i}$ is assigned a value to the household stock account, with 1 for hold and 0 for no hold. And the value is determined by the latent variable $Y_{i}^{*}$. When $Y_{i}^{*} \geq 0, Y_{i}=1$; When the $Y_{i}^{*} \leq 0, Y_{i}=0$; The size of $Y_{i}^{*}$ is jointly determined by the net value of the housing ( net_house ${ }_{i}$ ), whether the housing provident fund is owned ( if_hf $_{i}$ ), other control variables $X_{i}$, and random variables $\varepsilon_{i}$ that depict other invisible family characteristics

$$
\begin{gathered}
Y_{i}=1\left(Y_{i}^{*} \geq 0\right) \\
Y_{i}^{*}=\alpha_{1} \cdot \text { net_house }{ }_{i}+\alpha_{2} \cdot \text { if_hf }_{i}+\beta_{1} X_{i}+\varepsilon_{i}
\end{gathered}
$$

In Equation (11), $\varepsilon_{i}$ follows a normal distribution. $\alpha_{1}, \alpha_{2}, \beta_{1}$ are parameters to be estimated whether there is if_hf of provident fund. These parameters can be estimated by maximum relief estimation. 
Since the proportion of stock in current assets $X_{i}$ is truncated and between the range $[0,1]$, Tobit regression is needed in this paper to investigate the impact of home equity and whether the housing provident fund has on it. For family, its holdings of stocks accounted for the proportion of liquid assets for $Z_{i}$, it consists of home-equity [ net_house ${ }_{i}$ ], whether have reserve [if_hf ${ }_{i}$ ], other control variables, and invisible family traits $\eta_{i}$ determined by:

$$
Z_{i}=\max \left(\alpha_{1}^{*} \cdot \text { net_house }{ }_{i}+\alpha_{2}^{*} \cdot \text { if_hf }_{i}+\beta_{1}^{*} X_{i}+\eta_{i}, 0\right)
$$

$\alpha_{1}^{*}, \alpha_{2}^{*}, \beta_{1}^{*}$ are parameters to be estimated. The maximum likelihood estimation can also be used to estimate the parameters of Equation (12).

Home equity is an exogenous variable of housing wealth excluding housing loans, and its changes largely come from the fluctuation of China's housing market-the change of house prices. For investors, the correlation between changes in net housing value and household or household characteristics is weak. Therefore, there is no interference of endogenous problems with the net housing value as an independent variable. In our country, Housing provident fund refers to state organs and institutions, state-owned enterprises, urban collective enterprises, enterprises with foreign investment, urban private enterprises and other urban enterprises and institutions, private non-enterprise units, social organizations and their on-the-job staff and workers, Equivalent long-term housing savings is also an exogenous variable. Therefore, there is no endogenous interference with housing net value and provident fund as explanatory variables.

\section{Results of Empirical Analysis}

In the following two tables, column (I) is the result of the impact of net housing value and ownership of provident funds on whether households participate in the stock market. The second part is the robit regression result of the effect of housing net value and whether holding provident fund on family stock holding rate. Among them, Table 3 is the marginal effect, which can describe the impact of housing net value more directly; Table 4 is the obit coefficient, which explains the impact of owning provident fund on family stock decision-making.

First of all, it starts with the analysis of the impact of net housing value on the participation rate and stock holding rate of the family stock market.

According to column: 1) in Table 3, the marginal effect is significantly positive at the $1 \%$ level while the other variables remain unchanged. This shows that the probability of family participation in the stock market will increase with the increase of net housing value. In the regression, the marginal effect obtained from the sample data is $P$, which indicates that if the net housing value rises (decreases) a sample standard deviation (0.0020856), The probability of households entering the 0.0176574 stock market rose (fell) by about 1.7 percentage points. In this sample, the probability of households holding stock accounts is only $12.43 \%$, that is, the change of household stock account ownership rate caused by a standard deviation of net housing value cannot be ignored in the economic sense. 2) In the column, the marginal effect is also significantly positive at the level of $1 \%$, 
Table 3. Results of benchmark regression.

\begin{tabular}{|c|c|c|}
\hline & Model I & Model II \\
\hline Dependent Variable & Ifinstock & Stock_ratio \\
\hline net_house & $\begin{array}{c}0.0176574^{* * *} \\
(0.0020856)\end{array}$ & $\begin{array}{c}0.0752509^{* * *} \\
(0.0093126)\end{array}$ \\
\hline if_hf & $\begin{array}{c}0.0574415^{\star * *} \\
(0.0053061)\end{array}$ & $\begin{array}{c}0.2390926^{* * *} \\
(0.0262311)\end{array}$ \\
\hline income & $\begin{array}{c}0.0222986^{* * *} \\
(0.0075852)\end{array}$ & $\begin{array}{l}0.0958003 \\
(0.037629)\end{array}$ \\
\hline num & $\begin{array}{c}0.0038782 \\
(0.0016391)\end{array}$ & $\begin{array}{c}0.0173393 \\
(0.0073645)\end{array}$ \\
\hline gender & $\begin{array}{c}-0.0238013^{\star * *} \\
(0.0046782)\end{array}$ & $\begin{array}{c}-0.1046691^{\star * *} \\
(0.0223019)\end{array}$ \\
\hline risk_prference & $\begin{array}{c}-0.0380847^{\star * *} \\
(0.0016582)\end{array}$ & $\begin{array}{c}-0.1825768^{\star * *} \\
(0.0081786)\end{array}$ \\
\hline age & $\begin{array}{c}0.0008488^{* * *} \\
(0.0001708)\end{array}$ & $\begin{array}{c}0.0006915^{* * *} \\
(0.000166)\end{array}$ \\
\hline TLA & $\begin{array}{c}0.0657982^{* * *} \\
(0.0046159)\end{array}$ & $\begin{array}{c}0.0755995 \\
(0.0053154)\end{array}$ \\
\hline Education & $\begin{array}{c}0.0255616^{* * *} \\
(0.0014083)\end{array}$ & $\begin{array}{c}0.0234857^{* * *} \\
(0.0014088)\end{array}$ \\
\hline Region & $\begin{array}{c}-0.0231033^{\star * *} \\
(0.0030182)\end{array}$ & $\begin{array}{c}-0.0164833^{* * *} \\
(0.0028823)\end{array}$ \\
\hline rural & $\begin{array}{c}-0.1100571^{\star * *} \\
(0.010489)\end{array}$ & $\begin{array}{c}-0.0850748^{\star * *} \\
(0.0100162)\end{array}$ \\
\hline Pseudo $^{2}$ & 0.3294 & 0.2824 \\
\hline Observations & 15765 & 15765 \\
\hline
\end{tabular}

Note: $(1)^{* * *}$, indicating that it is significant under $1 \%$; (2) the number in parentheses is the standard error of the coefficient; (3) the marginal effect in the table is $\frac{\partial E[Z \mid X]}{\partial X}$.

Table 4. Results of benchmark regression.

\begin{tabular}{ccc}
\hline & Model I & Model II \\
\hline Dependent Variable & Ifinstock & Stock_ratio \\
net_house & $0.1306128^{* * *}$ & $0.0752509^{* * *}$ \\
& $(0.01555)$ & $(0.0093126)$ \\
if_hf & $0.4248974^{* * *}$ & $0.2390926^{* * *}$ \\
& $(0.0396702)$ & $(0.0262311)$ \\
income & $0.1649434^{* * *}$ & 0.0958003 \\
& $(0.0561665)$ & $(0.037629)$ \\
num & 0.0038782 & 0.0173393 \\
& $(0.0016391)$ & $(0.0073645)$ \\
gender & $-0.176059^{* * *}$ & $-0.1046691^{* * *}$ \\
& $(0.034644)$ & $(0.0223019)$
\end{tabular}




\section{Continued}

\begin{tabular}{ccc}
\hline risk_prference & $-0.2817145^{* * *}$ & $-0.1825768^{* * *}$ \\
& $(0.0126052)$ & $(0.0081786)$ \\
age & $0.0008488^{* * *}$ & $0.0052586^{* * *}$ \\
& $(0.0001708)$ & $(0.0007852)$ \\
TLA & $0.4867122^{* * *}$ & $0.112299^{* * *}$ \\
& $(0.0343086)$ & $(0.0298585)$ \\
Education & $0.1890801^{* * *}$ & $0.1224312^{* * *}$ \\
& $(0.0106417)$ & $(0.0066733)$ \\
Region & $-0.1708965^{* * *}$ & $-0.1085803^{* * *}$ \\
& $(0.0223918)$ & $(0.0146903)$ \\
rural & $-0.814097^{* * *}$ & $-0.5102304^{* * *}$ \\
& $(0.0771699)$ & $(0.0533935)$ \\
Pseudo $\mathrm{R}^{2}$ & 0.3294 & 0.2824 \\
Observations & 15765 & 15765
\end{tabular}

Note: $(1)^{* * *}$, indicating that it is significant under $1 \%$; (2) the number in parentheses is the standard error of the coefficient.

that is, the increase of net housing value will significantly increase the holding rate of family stocks. In the regression, the marginal effect of $\mathrm{T}$ is obtained from the sample data, which indicates that if the net housing value rises (decreases) a standard deviation (0.0752509), Household equity holdings increase (decrease) by about a percentage point. In this sample, the average holding rate of family stock 0.00931267 .5 is only, that is, the change of family stock holding rate caused by a change in the net housing value of a standard deviation of $4.71 \%$ in the economic sense cannot be ignored. According to the data in Table 4, the coefficient is significantly positive at the level where the other variables remain unchanged. In the regression, according to the sample data, the coefficient obtained from the sample data shows that the family with provident fund is more likely to join the stock market than the family without provident fund. In the regression of $\mathrm{T}$, according to the 0.4248974 sample data, the coefficient is that owning a provident fund will increase the stock holding rate of the family by 0.2390926 .

In addition, From the regression results, we can see the influence of other factors on household stock market participation rate and stock holding rate: 1) Household annual income and total financial assets on household stock market participation rate and stock holding rate. Has a significant positive effect, It shows that households with higher incomes are more likely to enter the high-risk stock market: on the one hand, it is easier for them to overcome the cost of access to information. Families with higher incomes have, to a large extent, higher wealth accumulation or workplace status, and they are more likely to have access to more accurate investment information than families with lower incomes, which will improve their return on investment. Increase their total wealth and make them willing to hold more risky assets. This cyclical effect allows high-income households to hold a higher share of risky assets than 
low-income households. On the other hand, their absolute risk aversion is low, and the Engel coefficient of high-income families is lower, which makes them more willing to take the risk of capital markets. The quality of life of high-income families is less affected than that of low-income families, even if they suffer the same amount of loss. 2) The age of the head of household is positively correlated with the participation rate in the stock market. This may be due to the fact that, within a certain range, the older the head of household is and the more wealth he accumulates, the more willing he is to put some of his assets into the high-risk stock market (Yin Zhichao, et al., 2014) [28]. Wu Weixing et al. (2010)

[22] pointed out that the research on the participation rate of the stock market in particular shows a strong life cycle effect. That is, with the increase of age, people's stock holdings are U-shaped, first increase and then decrease. 3) the higher the educational level of the head of household, the more able it is to promote active household access to the stock market and to hold stocks. This may be because a higher level of education makes residents more willing to learn finance-related knowledge and more acutely capture relevant financial information in order to better assess their investment risks and thus participate more actively in investment (Vissing-Jorgensen, 2002) [29] 4) the degree of risk preference of the head of household has a great influence on the participation and stock holding rate of the household stock market. If the head of household is risk-biased, he is more willing to finance the high-risk capital market, then the stock participation rate and stock holding rate of the household will be very high. If the head of household is risk-averse, they prefer low-risk products such as bank savings and state bonds, and the stock market participation rate and stock holding rate of households will also be lower. (Hong et al., 2004; Guiso et al., 2008; Guisoand Paiella, 2008) [30]. 5) the more family members of the head of household, the higher the degree of participation of the family in the stock market. This may be because the more family members, the more total household income and the more disposable income of the family. 6) Urban residents are more willing to invest in stocks than rural residents, possibly because urban residents are generally higher than rural residents in terms of income and education. 7) residents of eastern cities (Beijing, Shanghai, Guangdong, etc.) are more willing to participate in the stock market than residents of central (Shanxi, Jilin, Heilongjiang, Anhui, etc.) western cities (Inner Mongolia, Guangxi, Chongqing, Sichuan, Guizhou, etc.). This may be because the economic development and education level of the eastern cities are much higher than those of the central and western cities.

\section{Conclusions}

Based on the data of Chinese household finance survey for 5 years, this paper examines the changes of housing net value and the impact of (CHFS) 201 housing provident fund on the proportion of residents participating in the stock market and the shareholding rate. The results show that the increase of net 
housing value or ownership of provident fund will significantly increase the participation rate and stock holding rate of household stock market.

With reference to the model of Raj Chetty et al. (2017), this paper divides housing wealth into housing net worth and housing loans, and mainly examines the impact of housing net worth on household stock market investment, that is, the wealth effect of housing. Changing the uncertain conclusions of previous studies on the impact of housing wealth on family stock participation can help us to gain an in-depth understanding of the linkage between the real estate market and stocks. In this paper, the provident fund variable is also added, the provident fund has the characteristics of special funds, which can reduce the monthly mortgage expenses of some families and reduce the repayment pressure, so the provident fund is related to explanatory variable housing. At the same time, the provident fund will also reduce the disposable income of some households and reduce the expenditure that households can spend on investing in the stock market, so the provident fund will also affect the choice of investment in the stock market. In order to make the parameters more effective to assess the impact of housing net value and provident fund, this paper also controls other related variables. The results of regression show that there is a significant positive correlation between housing net value and provident fund and the investment decision of family stock market. The parameters of other variables also send us some meaningful messages, such as: household income and assets are positively correlated with household stock market participation and holding rate.

In modern economic society, real estate and stock have become the two most important investment products in the global investment market. In China, the wave of reform and opening up has strongly promoted the growth of the two markets. After more than a decade of rapid growth, the total market capitalization of China's stock market has become the second largest in the world, second only to the United States. On the other hand, the real estate industry has become the pillar industry of our national economic development, and its market fluctuation is related to the lifeblood of the development of the whole national economy. As two key markets in modern economic society, both of them have the problem of imperfect related system at the same time. Therefore, the study of the correlation between the housing market and the stock market in family units can help the formulation of macroeconomic policies and the development of marketing business of securities companies to provide a certain theoretical basis. The policy adjustment of the real estate industry should adhere to the principle of gradual and orderly progress. The rapid adjustment of house prices will not only have an impact on the real estate market, but also bring linkage effect to China's stock market. As far as the marketing business of securities companies is concerned, we can carry out differentiated marketing according to whether the family has a provident fund or not, and use big data to promote products in order to obtain higher marketing results. 


\section{Conflicts of Interest}

The author declares no conflicts of interest regarding the publication of this paper.

\section{References}

[1] Irwin, F. and Blume, M.E. (1975) The Demand for Risk Assets. American Economic Review, 65, 900-922.

[2] Tobin, J. (1982) Asset Accumulation and Economic Activity: Reflections on Contemporary Macroeconomic Theory. University of Chicago Press, Chicago.

[3] Liao, W.-C., Zhao, D. and Sing, T.F. (2012) Risk Attitude and Housing Wealth Effect. IRES Working Paper Series. https://doi.org/10.2139/ssrn.1954508

[4] Joël, P. (2004) Wealth Information Acquisition and Portfolio Choice. The Review of Financial Studies, 17, 879-914. https://doi.org/10.1093/rfs/hhg056

[5] Chen, Y., Shi, Y. and Quan, W. (2015) Housing Wealth, Financial Market Participation and Family Portfolio Choice-Evidence from Chinese Cities. Financial Research, No. 4, 1-18.

[6] Gan, L., Yin, Z. and Tan, J. (2015) China Household Finance Survey Report 2014. Southwest University of Finance and Economics Press, Chengdu.

[7] Liu, T. and Song, B. (2017) Analysis of the Impact of Housing Wealth on Stock Investment Decision-Making. Finance \& Banking, No. 8.

[8] Fratantoni, M.C. (1998) Homeownership and Investment in Risky Assets. Econometrica, 58, 25-51.

[9] Grossman, S.J. and Laroque, G. (1990) Asset Pricing and Optimal Portfolio Choice in the Presence of Illiquid Durable Consumption Goods. Econometrica, 58, 25-51. https://doi.org/10.2307/2938333

[10] Marjorie, F. and Yamashita, T. (2002) Owner-Occupied Housing and the Composition of the Household Portfolio. American Economic Review, 92, 345-362. https://doi.org/10.1257/000282802760015775

[11] Chetty, R. and Szeidl, A. (2007) Consumption Commitments and Risk Preferences. The Quarterly Journal of Economics, 122, 831-877. https://doi.org/10.1162/qjec.122.2.831

[12] Yamashita, T. (2003) Owner-Occupied Housing and Investment in Stocks: An Empirical Test. Journal of Urban Economics, 53, 220-237. https://doi.org/10.1016/S0094-1190(02)00514-4

[13] Cocco, J. (2005) Portfolio Choice in the Presence of Housing. Review of Financial Studies, 18, 535-567. https://doi.org/10.1093/rfs/hhi006

[14] Chetty, R. and Szeidl, A. (2010) The Effect of Housing on Portfolio Choice. NBER Working Paper No. 1599.

[15] Denis, F. and Poulhes, M. (2014) The Effect of Housing on Portfolio Choice: A Reappraisal Using French Data. CREST Working Paper.

[16] Chetty, R. and Szeidl, A. (2010) The Effect of Housing on Portfolio Choice. NBER Working Paper, No. 1599. https://doi.org/10.3386/w15998

[17] Ye, D., Wei, L. and Zhou, L. (2015) An Analysis of the Influencing Factors of Family Risk Financial Assets Investment from the Perspective of Real Estate Holdings. Maternal Economics Review, No. 2.

[18] Chetty, R., Andor, L. and Szeidl, A. (2017) The Effect of Housing on Portfolio 
Choice. The Journal of Finance, 72, 1171-1212.

https://doi.org/10.1111/jofi.12500

[19] He, X., Shi, W. and Zhou, K. (2009) Background Risk and Resident Venture Financial Asset Investment. Economic Research, No. 2, 97-110.

[20] Xing, C. (2011) Participation Cost, Heterogeneity and Stock Market Investment: An Empirical Analysis Based on Urban Household Data. Southern Economy, No. 9, 13-17.

[21] Wu, Z. and Qi, T. (2007) Liquidity, Life Cycle and Portfolio Differences-Empirical Analysis of Chinese Investor Behavior Survey. Economic Research, No. 2.

[22] Wu, W., Yi, X. and Zheng, J. (2010) Investment Structure of Chinese Households: An Empirical Analysis Based on Life Cycle, Wealth and Housing. Economic Research, S1, 72-82.

[23] Zhao, Y. (2017) Research on Influencing Factors of Family Venture Financial Assets Investment: Empirical Research Based on CFHS Micro-Data. Caixuan, No. 27, 77-78.

[24] Wu, W. and Lu, X. (2013) Asset Allocation and International Comparison of Urban Households in China: An Analysis Based on Micro Data. International Financial Research, 10, 45-57.

[25] Zhou, M., Sun, L. and Liu, Y. (2011) Social Interaction, Relative Wealth Concern and Stock Market Participation. Financial Research, No. 2, 172-184.

[26] Li, Y., Li, Z., Dong, J. and Wu, W. (2015) Research on the Impact of Risk Attitude on the Diversification of Household Investment in China. Finance and Trade Econo$m y$, No. 7, 150-161.

[27] Liu, J. (2015) Heterogeneity of Urban Households and Venture Financial Asset Investment in China. Economic Issues, No. 3, 51-60.

[28] Yin, Z., Song, Q. and Wu, Y. (2014) Financial Knowledge, Investment Experience and Family Asset Choice. Economic Research, 4, 62-75.

[29] Vissing-Jorgensen, A. (2002) Toward an Explanation of Household Portfolio Choice Heterogeneity: Nonfinancial Income and Participation Cost Structures. NBER Working Paper, No. W8884. https://doi.org/10.3386/w8884

[30] Hong, H., Kubik, J.D. and Stein, J.C. (2004) Interaction and Stock-Market Participation. The Journal of Finance, 59, 137-163.

https://doi.org/10.1111/j.1540-6261.2004.00629.x

[31] Campbell, J.Y. (2006) Household Finance. The Journal of Finance, 6, 1553-1604. https://doi.org/10.1111/j.1540-6261.2006.00883.x 